\title{
FEMINISMO, IDENTIDADE E GÊNERO EM JUDITH BUTLER: APONTAMENTOS A PARTIR DE "PROBLEMAS DE GÊNERO"
}

\author{
FEMINISM, IDENTITY AND GENDER IN JUDITH BUTLER: NOTES FROM \\ “GENDER TROUBLE”
}

Flávio Henrique FIRMINO ${ }^{1}$ Patricia PORCHAT ${ }^{2}$

RESUMO: Pretende-se nesse artigo acompanhar a proposta inicial de Judith Butler em Problemas de Gênero, de que o gênero não é uma essência nem uma construção social, mas uma produção do poder. Tomando o feminismo como mote para discutir inicialmente a identidade, vemos sua questão se expandir para o gênero, em geral, e chegar à própria noção de sujeito. A partir da crítica genealógica de Michel Foucault e de sua noção de poder, Butler pretende realizar uma crítica das categorias de identidade e, especificamente, da identidade enquanto fundamento da ação política do feminismo.

PALAVRAS-CHAVE: Butler. Gênero. Identidade. Feminismo.

ABSTRACT: This article intends to follow the initial proposal of Judith Butler in Gender Trouble, that gender is not either an essence or a social construct, but a production of power. Taking feminism as a theme to initially discuss the identity, we see her question to expand to genre in general and get to the notion of subject. From the genealogical critique of Michel Foucault and his notion of power, Butler intends to perform a critique of identity categories and ,specifically, identity as the basis of feminist political action.

KEYWORDS: Butler. Gender. Identity. Feminism.

\section{Introdução}

No debate entre essencialismo e construtivismo em relação aos gêneros, feministas, antropólogos, sociólogos, historiadores, psicólogos e educadores jamais chegaram a um acordo. Aparentemente uma questão que parecia ser teórica revelou-se como fundamento de diretrizes dentro de movimentos sociais. Judith Butler surge nessa cena com uma proposta para as teorias de gênero que desloca a discussão para o campo dos efeitos do poder. Entender o gênero nesse contexto é condição fundamental para aqueles que hoje se debruçam sobre as

\footnotetext{
${ }^{1}$ Universidade Estadual Paulista (Unesp), Faculdade de Ciências e Letras, Araraquara - SP - Brasil. Mestre pelo programa de Pós-graduação em Educação Escolar. E-mail: flahenfir2@gmail.com.

${ }^{2}$ Universidade Estadual Paulista (Unesp), Faculdade de Ciências e Letras, Araraquara - SP - Brasil. Professora do Programa de Pós-Graduação em Educação Sexual. E-mail: patriciaporchat@ fc.unesp.br.
} 
transformações sociais relativas às sexualidades e às identidades de gênero. Problemas de gênero foi o marco inicial, em 1990, de um debate que até hoje vem sendo realizado em inúmeros países e em diversos campos do conhecimento acerca do gênero como fundamento para lutas políticas, bem como para o estabelecimento de atitudes de exclusão, preconceito e violência. Afinal, o que é o gênero?

\section{Feminismo, identidade e a crítica genealógica de Michel Foucault}

No livro Problemas de Gênero: feminismo e subversão da identidade (BUTLER, 2003), originalmente publicado em 1990 como Gender Trouble: feminism and the subversion of identity, a filósofa Judith Butler coloca em questão a identidade como fundamento da ação política do feminismo.

De acordo com a autora, as estruturas jurídicas contemporâneas engessam categorias de identidade nos termos da coerência exigida pela matriz heterossexual ${ }^{3}$. Nesse sentido, reafirmar a identidade da "mulher" como sujeito do feminismo não estaria justamente contribuindo para manter a estabilidade das relações hierárquicas entre masculino e feminino que se estabelecem no interior nessa matriz? Além disso, a presunção de uma identidade feminina pode, inintencionalmente, excluir sujeitos que não se enquadram nas exigências normativas dessa categoria. Afinal, quem é "a mulher"? Como defini-la? Qualquer que seja a resposta, a definição levará a um engessamento identitário no interior das relações engendradas pelo sistema de poder-saber (FOUCAULT, 2013) ao que o feminismo pretende se opor.

Nesse sentido, uma ação política comprometida com o desmantelamento das relações de hierarquia deveria focar não nas identidades - produtos ou efeitos do poder - mas nos processos de produção dessas identidades e manutenção das relações entre elas, empreendendo-se uma pesquisa genealógica que analise os mecanismos de poder que as tem como efeito.

Butler ${ }^{4}$ utiliza como instrumento de análise a crítica genealógica elaborada por Michel Foucault, presente em sua obra a partir dos livros publicados durante a década de 1970: Vigiar e punir (1975) e o primeiro volume da História da sexualidade, intitulado A vontade de saber

\footnotetext{
${ }^{3}$ De acordo com Butler, o termo "matriz heterossexual" designa a "[...] grade de inteligibilidade cultural por meio da qual os corpos, gêneros e desejos são naturalizados." (BUTLER, 2003, p.216). A autora utiliza esse termo a partir das noções de "contrato heterossexual", de Monique Wittig, e de "heterossexualidade compulsória", de Adrienne Rich.

${ }^{4}$ Neste artigo, todas as citações de Butler se referem à obra Problemas de Gênero: feminismo e subversão da identidade (BUTLER, 2003).
} 
(1976). E é em Microfísica do poder que Foucault (1979) aborda mais detalhadamente o funcionamento dos mecanismos de poder. Mas o que seria o poder em Foucault?

Para Foucault, o poder não deve ser entendido como uma "entidade" ou como uma "ideia" ou "identidade teórica". Em vez disso, deve ser compreendido como prática ou como exercício, que só existe em sua concretude, efetuado em níveis variados em múltiplas direções no cotidiano, a partir de instituições como a escola, a prisão, o hospício, o quartel, a fábrica, os meios de comunicação e as ciências (DANNER; OLIVEIRA, 2009; FOUCAULT, 1979; MUCHAIL, 2004).

Danner e Oliveira (2009) apontam que o poder em Foucault é compreendido como uma rede de micro-poderes articulados ao Estado e que atravessam a estrutura social, ou seja, como "[...] uma rede de dispositivos ou mecanismos que atravessam toda a sociedade e do qual nada nem ninguém escapa.” (DANNER; OLIVEIRA, 2009, p.787). Em oposição à noção do poder como centrado no Estado, detido pelos dominantes e imposto aos dominados sob a forma de proibições, punições, opressões, coações e constrangimentos, Foucault afirma que seria um equívoco qualificar e reduzir o poder essencialmente em seu aspecto repressivo. Seria preciso dar destaque à face produtiva do poder, expressa por meio de incitações, induções e imperativos, que através de práticas disciplinares objetivam corpos dóceis, úteis e produtivos, necessários ao bom funcionamento da economia (DANNER; OLIVEIRA, 2009; FOUCAULT, 1979; MUCHAIL, 2004).

O poder se articula intrinsecamente ao saber. O que conhecemos, as formas pela qual conhecemos e mesmo o sujeito que conhece são efeitos da implicação entre poder e saber e suas transformações históricas (FOUCAULT, 2013). O sexo como objeto do conhecimento, por exemplo, não pode ser analisado como externo ao poder ou anterior ao que se sabe sobre ele, mas como um produto da relação poder-saber que pode ser compreendido ao apreendê-lo como um objeto que tem caráter histórico e está fundamentalmente implicado em uma rede de práticas em exercício que ao descrever, classificar e analisar objetos, acabam por constituí-los. Tal constituição atende a objetivos estratégicos e faz parte dessa estratégia ocultar-se, afirmando como naturais e causais categorias que ela mesma institui (FOUCAULT, 1988). De acordo com Butler:

Ao postular o "sexo" como "causa" das experiências sexuais, do comportamento e do desejo a produção tática da categorização descontínua e binária do sexo oculta os objetivos estratégicos do próprio aparato de produção. A pesquisa genealógica de Foucault expõe essa "causa" ostensiva como um "efeito", como a produção de um dado regime de sexualidade que busca regular a experiência sexual instituindo as categorias distintas do sexo 
como funções fundacionais e causais, em todo e qualquer tratamento discursivo da sexualidade. (BUTLER, 2003, p. 46, grifo do autor).

O que a genealogia de Foucault pretende é analisar os mecanismos de poder nos termos descritos acima - enquanto exercício e articulado ao saber - e que tem como efeito o sujeito. Butler parte dessa ferramenta para realizar uma crítica à categoria de identidade, mais especificamente, à identidade do sujeito do feminismo:

A identidade do sujeito feminista não deve ser o fundamento da política feminista, pois a formação do sujeito ocorre no interior de um campo de poder sistematicamente encoberto pela afirmação desse fundamento. (BUTLER, 2003, p. 23).

É nesse sentido que a crítica genealógica se torna útil no pensamento de Butler: para denunciar a captura da identidade nas redes de poder-saber e apontar a necessidade de um novo tipo de política feminista.

[...] talvez um novo tipo de política feminista seja agora desejável para contestar as próprias reificações do gênero e a identidade - isto é, uma política feminista que tome a construção variável da identidade como um pré-requisito metodológico e normativo, senão como um objetivo político. (BUTLER, 2003, p. 23).

O aparente fracasso em partir da identidade para fundamentar a política feminista leva a questioná-la e a tentar apreender essa categoria sob outro paradigma que não o da metafísica da substância ou da construção. A inovação na forma de "fazer política" precisa da inovação na forma de conceber o sujeito, a noção de identidade e, por conseguinte, a identidade de gênero, considerando que nossa identidade só se torna inteligível quando é "genderificada". É preciso, então, questionar a concepção de gênero, com o intento político de torná-lo um instrumento eficaz na política feminista.

Afinal, quando falamos na identidade do sujeito do feminismo, "a mulher", sob qual perspectiva é possível apreendê-la de forma a realizar transformações políticas que sejam de fato potentes? Seria possível deslocar o sujeito do feminismo?

\section{A biologia ou a cultura como destino: gênero como essência ou construção}

Butler explica que o conceito de gênero foi forjado como oposição ao determinismo biológico existente na ideia de sexo, que implica na biologia como um destino: o sujeito 
nasceria homem ou mulher e suas diferentes experiências e lugares na sociedade seriam determinados naturalmente de acordo com o sexo que o sujeito nasceu. Essa determinação biológica serve à naturalização da desigualdade entre homens e mulheres. Ao se naturalizar o poder, oculta-se como seus mecanismos operam, bem como a possibilidade de contestação e transformação da estrutura social. $O$ conceito de gênero surge então para afirmar que as diferenças sexuais não são por si só determinantes das diferenças sociais entre homens e mulheres, mas são significadas e valorizadas pela cultura de forma a produzir diferenças que são ideologicamente afirmadas como naturais.

A autora argumenta que, no entanto, a noção do gênero como construção pode também levar a um tipo de determinismo, não biológico, mas cultural.

[...] a ideia de que o gênero é construído sugere um certo determinismo de significados do gênero, inscritos em corpos anatomicamente diferenciados, sendo esses corpos compreendidos como recipientes passivos de uma lei cultural inexorável. Quando a 'cultura' relevante que 'constrói' o gênero é compreendida nos termos dessa lei ou conjunto de leis, tem-se a impressão de que o gênero é tão determinado e tão fixo quanto na formulação de que a biologia é o destino. Nesse caso, não a biologia, mas a cultura se torna o destino. (BUTLER, 2003, p.26, grifo nosso).

Se entendermos o gênero como uma construção cultural, que difere de sexo, um corpo que ao nascer tem vagina ainda não é mulher. Mas justamente nesse ainda não haveria um determinismo cultural que diz que quem nascer com vagina será uma mulher? Se a biologia não é destino, a cultura o seria?

Para Simone de Beauvoir (1970) "não se nasce mulher, torna-se”. Butler dirá que essa afirmação parece sugerir que o gênero é variável e volitivo, comportando uma dimensão de escolha e de agência por parte do sujeito, na possibilidade de tornar-se algo que não está dado a priori. Essa suposta possibilidade de escolha nos leva a perguntar: o que determina o que nos tornamos? De que maneira nos tornamos isso? Em que medida alguém escolhe seu gênero? De acordo com Butler, Beauvoir afirma que "se torna mulher", mas sempre sob uma compulsão cultural a fazê-lo. Nesse momento do texto, Butler não aprofunda essa ideia de escolha feita sob uma compulsão cultural. No entanto, Beauvoir (1970) nos leva a pensar que a suposta escolha implícita no "tornar-se" é sempre feita no contexto de um imperativo cultural a fazê-la. Há no sujeito que nasce com vagina, por exemplo, um tornar-se que parece sugerir uma escolha, mas que no contexto da heterossexualidade compulsória ${ }^{5}$ será

5 No contexto da discussão da existência lésbica no pensamento feminista, a poeta, professora e crítica estadunidense Adrienne Rich propôs a ideia da heterossexualidade compulsória como, a grosso modo, uma 
apresentada ao sujeito como um imperativo, uma ordem: "torne-se mulher!", mesmo que essa ordem seja dada de forma mais ou menos sutil. Ainda que haja no descolamento entre sexo e gênero e no "tornar-se" um livre arbítrio que permitiria ao sujeito, seja de qual sexo for, tornar-se homem ou mulher, essa "escolha" é feita no contexto de uma cultura e de um regime de poder que colocam imperativos aos sexos. Nesse sentido, o livre arbítrio de nossas escolhas em relação ao gênero está em constante oposição ou negociação com um conjunto de normas que dizem como devemos nos comportar, o que devemos vestir e a quem devemos desejar tendo como base nosso sexo. Escapamos do determinismo biológico, mas não da compulsão cultural que utiliza o sexo como referência.

Butler também argumenta que “[...] não há como recorrer a um corpo que já não tenha sido sempre interpretado por meio de significados culturais." (BUTLER, 2003, p.27). Diante desse argumento, podemos pensar em como o corpo é envolvido pelo discurso desde a concepção: no momento do ultrassom, o enunciado "é uma menina!" ou "é um menino!" já insere o bebê no discurso cultural sobre o que é ser menino ou menina. Toda uma expectativa social é mobilizada sobre quem aquele sujeito irá desejar, do que irá brincar e de que cores serão suas roupas. Seu corpo está, desde o início, marcado por significados culturais. Nesse sentido, Butler argumenta que "[...] o sexo não poderia qualificar-se como uma facticidade anatômica pré-discursiva." (BUTLER, 2003, p.27), o sexo é gênero desde o começo. Neste ponto, Butler propõe um giro que consiste em afirmar que, assim como o gênero, o sexo também é produzido discursivamente. Ou seja, o sexo - tal como o gênero - não é anterior ao discurso: é, em vez disso, um efeito do discurso. Assim, considera que nem mesmo o sexo existe pré-discursivamente. Não é uma substância ou essência, mas uma produção ou efeito discursivo.

\section{Identidade, gênero e sujeito como produção}

Butler se opõe à metafísica da substância, ou seja, à crença de que o sexo e o gênero são entidades naturais. A posição da autora nos leva a pensar que há uma razão política para afirmar o gênero e o sexo como substância/essência. É preciso afirmar a substância dos gêneros dentro do binarismo masculino-feminino para apontar sua naturalidade e supor sua complementariedade, o que afirma a suposta naturalidade do desejo entre "homens" e "mulheres". Com isso, o caráter compulsório da heterossexualidade é mascarado e o regime 
de poder se fortalece, já que não nos é apresentado como um regime, como uma lei que é imposta, mas como um fato natural da vida. Sendo natural, como questioná-lo? Estando sua característica repressora oculta pela naturalização, como questionar a opressão de um regime político se ele se apresenta como uma lei natural ou nem mesmo como uma lei, mas como um desejo natural? Essa naturalização e essencialização do gênero e do desejo heterossexual é amplamente operada nas milhares de imagens que são veiculadas nas novelas, filmes, desenhos, materiais didáticos, revistas e na publicidade. Na verdade, o que se vende é a ideia da heterossexualidade como a única forma viável de existência.

Segundo Butler (2003, p.37) “[...] as pessoas só se tornam inteligíveis ao adquirir seu gênero em conformidade com padrões reconhecíveis de inteligibilidade de gênero." Por isso, a discussão sobre a identidade não pode vir antes da discussão sobre a identidade de gênero. Se as pessoas precisam ser reconhecidas como homens ou mulheres para "ter" uma identidade de gênero e consequentemente uma identidade inteligível, e essas categorias - homem e mulher - dizem respeito a uma produção discursiva, tem-se que a própria identidade é uma produção discursiva, um efeito do discurso. Nesse sentido, o sujeito não é anterior ao que ele expressa, mas é justamente um efeito do que ele expressa.

[...] o gênero é sempre um feito, ainda que não seja obra de um sujeito tido como preexistente à obra. [...] não há identidade de gênero por trás das expressões do gênero; essa identidade é performativamente constituída, pelas próprias "expressões" tidas como seus resultados. (BUTLER, 2003, p. 48, grifo do autor).

"Ser homem", por exemplo, não se trata de uma identidade masculina que seja anterior à expressão de atos masculinos. Não há uma identidade que seja anterior e causa dos meus atos. São esses atos, feitos repetidamente, que produzem a aparência de uma substância fixa e estável, que produzem uma identidade masculina que tem a aparência de ser permanente, ainda que seja instável e exija um fazer contínuo de atos culturalmente significados como masculinos. Assim, o gênero não é algo que somos, mas algo que fazemos (SALIH, 2013).

Para Butler, atos, gestos e atuações produzem o efeito de um núcleo ou substância interna. Esses atos são performativos, no sentido de que a identidade que pretendem expressar é fabricada por eles, "[...] manufaturadas e sustentadas por signos corpóreos e outros meios discursivos.” (BUTLER, 2003, p.194). Eles criam a ilusão de um núcleo interno e regular do gênero, o que serve ao propósito político de regular a sexualidade nos termos da heterossexualidade compulsória. Ao deslocar a origem ou causa do gênero para um núcleo 
psicológico, impede-se a análise da rede de discursos na qual o gênero é engendrado, já que esta é invisibilizada.

O gênero é a estilização repetida do corpo, um conjunto de atos repetidos no interior de uma estrutura reguladora altamente rígida, a qual se cristaliza no tempo para produzir a aparência de uma substância, de uma classe natural de ser. (BUTLER, 2003, p. 59).

De acordo com Butler, gêneros inteligíveis são aqueles que “[...] instituem e mantém relações de coerência e continuidade entre sexo, gênero, prática sexual e desejo.” (BUTLER, 2003, p.38). Ainda para a autora, essa matriz cultural, "[...] por intermédio da qual a identidade de gênero se torna inteligível exige que certos tipos de 'identidade' não possam 'existir'." (BUTLER, 2003, p.39). A coerência da identidade de gênero e a existência de gêneros inteligíveis exigem que certas configurações entre sexo, gênero, práticas sexuais e desejo sejam excluídas. Trata-se de um regime de poder, portanto, que garante a existência de certas identidades ao preço da exclusão de outras: para que A exista e tenha sentido, B, C e D não devem existir.

No entanto, não apenas a possibilidade, mas a própria existência da configuração de atributos como sexo, desejo, gênero e práticas sexuais fora da sequência habitual e hegemônica denuncia essa sequência como também sendo um arranjo artificial, produzido, em vez de uma substância ou essência. Ou seja, a denúncia do caráter produzido do gênero e a visualização de seus atributos de forma descontínua nos faz questionar a artificialidade da continuidade do que antes víamos como sólido e permanente. É o que acontece no caso Herculine Barbin, um/uma hermafrodita do século XIX que não pode ser classificada/o nos termos de um binarismo heterossexual que estabelece uma correlação simples entre sexo e gênero e que classifica as pessoas em macho/fêmea ou masculino/feminino. A própria existência de Herculine atenta contra a coerência da matriz heterossexual ao denunciar sua instabilidade.

Se a noção de uma substância permanente é uma construção fictícia, produzida pela ordenação compulsória de atributos em sequências de gênero coerentes, então o gênero como substância, a viabilidade de homem e mulher como substantivos, se vê questionado pelo jogo dissonante de atributos que não se conformam aos modelos sequenciais ou causais de inteligibilidade. (BUTLER, 2003, p. 47, grifo do autor).

No terceiro capítulo de Problemas de gênero, Butler discute com mais clareza o potencial de descontinuação da matriz heterossexual que certos corpos desempenham com 
seus atos e que impossibilitam que falemos em gêneros verdadeiros ou falsos, já que qualquer gênero pode ser entendido nos termos de uma imitação. Nesse sentido, não há como pensar em original e imitação, como se, por exemplo, o gênero da travesti fosse uma imitação do "gênero original" da "mulher". Tanto a travesti quanto a mulher desempenham atos que tem como efeito a produção de uma identidade considerada feminina. Em vez de ser uma cópia ou imitação da mulher original, a travesti ou a drag, ao revelar o caráter da performatividade do gênero em seus atos, gestos e atuações apontam para o fato de que também a mulher dita original tem sua identidade produzida pela repetição estilizada desses mesmos atos, gestos e atuações, considerados em nossa cultura como femininos. Assim, a existência de um "ser" que descontinua a sequência habitual entre sexo anatômico e gênero aponta a descontinuidade que há na aparente unidade e solidez da mulher original: os elementos de sua identidade contínua - sexo e gênero - passam a ser vistos como separados: o sexo não necessariamente determina o gênero e, assim como a drag ou a travesti, a mulher "de verdade" precisou tornarse mulher, em um processo que nada tem de natural e automático. A inscrição de signos de feminilidade se fez por um esforço normatizante no contexto da heterossexualidade compulsória e sua compulsão por binarismos. Nesse sentido, Butler afirma que

[...] o travesti também revela a distinção dos aspectos da experiência do gênero que são falsamente naturalizados como uma unidade através da ficção reguladora da coerência heterossexual. Ao imitar o gênero, o drag revela implicitamente a estrutura imitativa do próprio gênero - assim como sua contingência. (BUTLER, 2003, p. 196, grifo do autor).

No bojo dessa reflexão, Butler apresenta a noção de paródia de gênero, afirmando que ela não presume a existência de um original que essas identidades parodísticas imitem.

\footnotetext{
Aliás, a paródia que se faz é $d a$ própria ideia de um original [...], a paródia do gênero revela que a identidade original sobre a qual molda-se o gênero é uma imitação sem origem. [...] a identidade de gênero pode ser reconcebida como uma história pessoal/cultural de significados recebidos, sujeitos a um conjunto de práticas imitativas que se referem lateralmente a outras imitações e que, em conjunto, constroem a ilusão de um eu de gênero primário e interno marcado pelo gênero, ou parodiam o mecanismo dessa construção. (BUTLER, 2003, p. 197, grifo do autor).
}

Assim, Butler parece sugerir que o "original" é na verdade o efeito de um discurso originário, que contínua e historicamente se inscreve nos sujeitos e nas relações entre eles, originando corpos que com o passar do tempo adquirem o status de originais. 
A denúncia realizada pelos corpos "incoerentes" ataca o próprio sistema de podersaber que nega sua inteligibilidade. Faz-se um movimento inverso: denuncia-se a ininteligibilidade do sistema que confere inteligibilidade, pois se determinados corpos "não cabem" em seu esquema, ele não serve para explicar o gênero. Questionar seu saber sobre o gênero implica em, ao mesmo tempo, questionar seu poder. Quando o corpo extrapola as fronteiras que tentam delimitá-lo e regulá-lo, acaba por implodir o sistema que tentava capturá-lo, pois subverte sua lógica e denuncia sua impotência explicativa. Diferentemente de uma política que afirma as identidades produzidas no interior desse sistema, o questionamento da coerência identitária ataca a própria ordem que tenta instituí-la, embaralhando noções que sustentam mecanismos de poder responsáveis pela produção de corpos dóceis.

A elaboração da concepção de identidade, gênero e sujeito como produção permite focar a ação política na análise dos mecanismos de poder que engendram essas produções, sem que seja necessário partir de uma identidade pré-definida para definir essa ação. Até mesmo o questionamento dessas categorias a partir da noção de produção é necessário para resistir a engessamentos.

Vimos que Butler, ao desenvolver a noção de gênero como ato performativo, coloca a identidade como efeito desses atos que, com o tempo, adquire a aparência de substância. Essa noção também leva ao deslocamento do sujeito da posição de anterioridade e causa dos atos para a posição de efeito desses atos executados repetidamente. A partir dessas novas concepções de identidade e sujeito, o sujeito do feminismo pode ser deslocado da identidade "mulher" para um não-lugar onde ele não tem uma definição precisa, no sentido de que é constituído na medida em que age, atua e luta contra engessamentos, imposições e induções. O não-lugar do sujeito do feminismo não o livra de ser engendrado pelos mecanismos de poder, mas permite que "ele" tenha maior liberdade de movimentos e maior potencial de resistência contra aquilo que ao tentar defini-lo, o imobiliza. A multiplicidade de atos e de formas de ser e de existir se constitui como a força criativa necessária ao escape de categorias identitárias e à desorganização de sequências normatizadoras. Escapar à categoria "mulher" como fundacional para o feminismo abre um campo de manobra para combater uma matriz que encontra seu potencial de "assujeitamento" justamente na imobilidade das identidades.

\section{REFERÊNCIAS}

BEAUVOIR, S. O segundo sexo. Tradução de Sérgio Milliet. 4.ed. São Paulo: Difusão Européia do Livro, 1970. 
BUTLER, J. Problemas de gênero: feminismo e subversão da identidade. Tradução de Renato Aguiar. Rio de janeiro: Civilização Brasileira, 2003.

DANNER, F.; OLIVEIRA, N. A genealogia do poder em Michel Foucault. In: MOSTRA DE PESQUISA DA PÓS-GRADUAÇÃO, 4., 2009, Porto Alegre. Anais... Porto Alegre: PUCRS, 2009. p.786-794.

FOUCAULT, M. Vigiar e punir: história da violência nas prisões. 41.ed. Petrópolis: Vozes, 2013.

FOUCAULT, M. História da sexualidade I: a vontade de saber. 13.ed. Rio de Janeiro: Edições Graal, 1988.

FOUCAULT, M. Microfísica do poder. Rio de Janeiro: Edições Graal, 1979.

MISKOLCI, R. Teoria Queer: um aprendizado pelas diferenças. Belo Horizonte: Autêntica: UFOP, 2012. (Série Cadernos da Diversidade, 6).

MUCHAIL, S. T. Foucault, simplesmente. São Paulo: Edições Loyola, 2004.

RICH, A. Heterossexualidade compulsória e existência lésbica. Tradução de Carlos Guilherme do Valle. Revista Bagoas, Natal, v.4, n.5, p.17-44, jan./jun. 2010.

SALIH, S. Judith Butler e a Teoria Queer. Tradução de Guacira Lopes Louro. Belo Horizonte: Autêntica, 2013.

\section{Como referenciar este artigo}

FIRMINO, Flávio Henrique.; PORCHAT, Patrícia. Feminismo, identidade e gênero em Judith Butler: apontamentos a partir de "problemas de gênero". Doxa: Rev. Bras. Psicol. Educ., Araraquara, v.19, n.1, p. 51-61, jan./ jun. 2017. ISSN: 1413-2060.

Submetido em: 10/12/2016

Aprovado em: 28/03/2017 